\title{
Idiopathic Granulomatous Mastitis: Comparison of Wide Local Excision with or without Corticosteroid Therapy
}

\author{
Alper Akcan A. Bahadır Öz Serap Dogan Hülya Akgün \\ Muhammet Akyüz Engin Ok Mustafa Gök Tutkun Talih \\ Department of General Surgery, Erciyes University School of Medicine, Kayseri, Turkey
}

\section{Keywords}

Idiopathic granulomatous mastitis - Wide excision .

Corticosteroid therapy

\section{Summary}

Background: Idiopathic granulomatous mastitis (IGM) is an uncommon chronic inflammatory disease of the breast with uncertain optimal treatment regimen. In this study, our purpose was to report our clinical experience with 74 IGM patients who were treated wide local excision with or without steroid therapy. Patients and Method: 74 cases diagnosed histologically as IGM were identified from surgical and pathological records between January 1995 and January 2012. Group 1 (surgery-only group) comprised 53 patients, and the 21 patients in group 2 were treated with corticosteroids prior to surgical treatment (steroid-and-surgery group). Results: Follow-up data were complete for 67 (91.7\%) of the 73 patients. Recurrence developed in 4 (7.5\%) patients in the surgery-only group, while there was no recurrence in the steroid-and-surgery group; the difference was not statistically significant $(p=0.19)$. Conclusion: Systemic steroid therapy with surgical resection is the recommended first-line treatment strategy for IGM.

\section{Introduction}

Idiopathic granulomatous mastitis (IGM) is a rare chronic inflammatory disease of the breast which was first described in 1972 [1]. Although it is benign, its clinical and radiological features often mimic breast carcinoma [2]. It may also be difficult to distinguish from infective mastitis and inflammatory breast disease of known etiology. The etiology of IGM is unknown, but some authors have speculated that the cause may be an autoimmune process, undetected microorganisms, use of oral contraceptives, or a reaction to childbirth [3]. IGM is characterized pathologically by the presence of chronic granulomatous lobulitis in the absence of an obvious etiology [1, 4].
Although the frequency of IGM is increasing fast, only a few hundred cases have been reported worldwide [5,6]. At present, there is still no universally accepted management strategy for IGM. Use of corticosteroids and antibiotics, abscess drainage, and wide local excision of the lesions have been reported for the treatment of IGM [7, 8]. Because of the lack of prospective randomized studies, the management of IGM remains controversial. Nonetheless, wide local excision with or without steroid therapy is most commonly advocated $[9,10]$. In this study, our purpose was to report our clinical experience with 74 IGM patients who were treated by wide local excision with or without steroid therapy, and we believe that this is the largest series reported in the literature.

\section{Patients and Methods}

From surgical and pathological records from between January 1995 and January 2012, 74 cases diagnosed histologically as IGM were identified. These patients represented $2.7 \%$ of all patients who underwent surgery for breast diseases in our clinic during the study period. A careful history was taken and a thorough physical examination was performed. Diagnosis of IGM was confirmed histologically in all cases by core needle or excisional biopsy. All slides were examined with hemotoxylin-eosin $(\mathrm{H} \& \mathrm{E})$ staining and special stains such as Gram, Ziehl-Neelson, and periodic acid-Schiff. Mammographic examinations were performed in craniocaudal and mediolateral oblique positions. 64 patients were examined with mammography (MMG), 73 had ultrasonography (US), and 31 had magnetic resonance imaging (MRI). In 9 patients, mammographic evaluation was not performed due to the young age of the patients and benign clinical impression. Fine-needle aspiration (FNA) biopsy was performed in 37 patients.

Patients underwent either only surgery or steroid treatment prior to surgery. The criteria for selecting the method of initial treatment (steroid or surgery) depended on the dimensions of the lesion, the severity of the symptoms, and the patient's general health and personal treatment preferences.

The patients were divided into 2 groups according to the treatment regimen. Group 1 (surgery-only group) comprised 53 patients, and the 21 patients in group 2 were treated with corticosteroids prior to surgical treatment (steroid-and-surgery group)

Statistical analysis was performed using SPSS version 15.0 (SPSS Inc., Chicago, IL, USA) by the biomedical informatics team. Comparisons

\section{KARGER}

Fax +497614520714

Information@Karger.com

www.karger.com (c) 2014 S. Karger GmbH, Freiburg

$1661-3791 / 14 / 0092-0111 \$ 39.50 / 0$

Accessible online at:

www.karger.com/brc
Abdullah Bahadır Öz, MD

Department of General Surgery

Erciyes University School of Medicine

Kayseri 38039, Turkey

drbahadir01@gmail.com 
between groups were made using Pearson's $\chi^{2}$ test or Fisher's exact test. A $p$ value $<0.05$ was accepted as significant.

\section{Results}

\section{Clinical Features}

The clinical features of all patients with IGM are shown in table 1 . The mean age of the patients and the median number of pregnancies were not statistically different between the surgery-and-steroid group and the surgery-only group ( $\mathrm{p}=$ 0.93 and $\mathrm{p}=0.82$, respectively). The most common presenting symptoms were a mass in the breast $(58 \%$ and $66 \%)$ and pain (30\% and $38 \%$ ) in the surgery-only group and the steroidand-surgery group, respectively. The masses were quite hard and clinically measured $1.5-12.5 \mathrm{~cm}$ (mean $4.4 \mathrm{~cm}$ ) in size in the surgery-only group and $1.7-11.2 \mathrm{~cm}$ (mean $4.8 \mathrm{~cm}$ ) in the steroid-and-surgery group. The other most common physical examination findings were overlying skin inflammation (22.6\% and $19 \%)$, nipple inversion $(9.4 \%$ and $15 \%)$, axillary lymphadenopathy $(13.2 \%$ and $14.2 \%)$, and fistula $(7.5 \%$ and $14.2 \%$ ) (fig. 1) in the surgery-only group and the steroid-andsurgery group, respectively. Synchronous or metachronous involvement of the contralateral breast was not found.

\section{Radiologic Evaluation}

In the surgery-only group, mammographic examination showed an asymmetric density with no distinct margins in 22 patients and an ill-defined mass in 15 patients. In 7 cases, the parenchymal breast pattern was dense, and no abnormal findings were detected on MMG. In the steroid-and-surgery group, mammographic examination showed an asymmetric density with no distinct margins in 12 patients (fig. 2) and an ill-defined mass in 4 patients. In 4 cases, the parenchymal breast pattern was dense, and no abnormal findings were detected on MMG. In the surgery-only group, sonographic examination showed an irregular hypoechoic mass in 27 patients, hypoechoic nodular structures in 17 , and focally decreased parenchymal echogenicity with acoustic shadowing in 7 patients. US was normal in 2 patients. In the steroid-andsurgery group, sonographic examination showed an irregular hypoechoic mass in 12 patients, hypoechoic nodular structures in 6 , and focally decreased parenchymal echogenicity with acoustic shadowing in 2 patients. US was normal in 1 patient. In the surgery-only group, MRI was performed preoperatively in 19 patients and in 3 patients postoperatively. In the steroid-and-surgery group, MRI was performed preoperatively in 9 patients. MRI showed focal homogenous enhancing masses with irregular borders in 13 patients, parenchymal distortion in 15 , and parenchymal asymmetry in 2 patients (fig. 3). In 1 patient, MRI showed ring-like abscess formation 1 month after excision. In 47 patients $(64.3 \%)$, the clinical and radiological findings before surgery suggested a malignant neoplasm. In 17 patients $(23.3 \%)$, benign breast disease such as periductal mastitis, intraductal papilloma, and fibroadenoma was considered.

\section{Histopathologic Evaluation}

The FNA results were benign in 22 patients, malignant in 3 , and inconclusive in 12 patients because of insufficient material or nonspecific inflammatory findings. Frozen-section

Table 1. Clinical characteristics of the patients with IGM

\begin{tabular}{|c|c|c|c|}
\hline Characteristic & Group I (surgery-only), $\mathrm{N}=53$ & Group II (surgery-and-steroid), $\mathrm{N}=21$ & $\mathrm{p}$ \\
\hline Age (mean \pm standard deviation), years & $37.3 \pm 12.3$ & $34.8 \pm 11.7$ & 0.93 \\
\hline Median number of pregnancies, $\mathrm{n}$ (range) & $2(0-6)$ & $3(0-5)$ & 0.82 \\
\hline Mass size, mean (range), $\mathrm{cm}$ & $4.4(1.5-12.5)$ & $4.8(1.7-11.2)$ & 0.77 \\
\hline Lactation in last 1 year, $\mathrm{n}$ & & & 0.49 \\
\hline Yes & 6 & 3 & \\
\hline No & 47 & 18 & \\
\hline Medication allergy, $\mathrm{n}$ & & & 0.55 \\
\hline Yes & 4 & 2 & \\
\hline No & 49 & 19 & \\
\hline Oral contraceptive use, $\mathrm{n}$ & & & 0.60 \\
\hline Yes & 7 & 3 & \\
\hline No & 44 & 18 & \\
\hline BCG vaccination, $n$ & & & 0.48 \\
\hline Yes & 52 & 20 & \\
\hline No & 1 & 1 & \\
\hline Type of surgery, $n$ & & & 0.59 \\
\hline Excision & 6 & 2 & \\
\hline Wide local excision and quadrantectomy & 47 & 19 & \\
\hline Smoking, $\mathrm{n}$ & & & 0.96 \\
\hline Yes & 14 & 6 & \\
\hline No & 39 & 15 & \\
\hline Side, $\mathrm{n}$ & & & 0.99 \\
\hline Left & 31 & 13 & \\
\hline Right & 22 & 8 & \\
\hline Cosmesis of the breast, $\mathrm{n}$ & & & 0.20 \\
\hline Good to average & 45 & 20 & \\
\hline $\mathrm{Bad}$ & 8 & 1 & \\
\hline Local recurrence & $4 / 53$ & $0 / 21$ & 0.19 \\
\hline
\end{tabular}




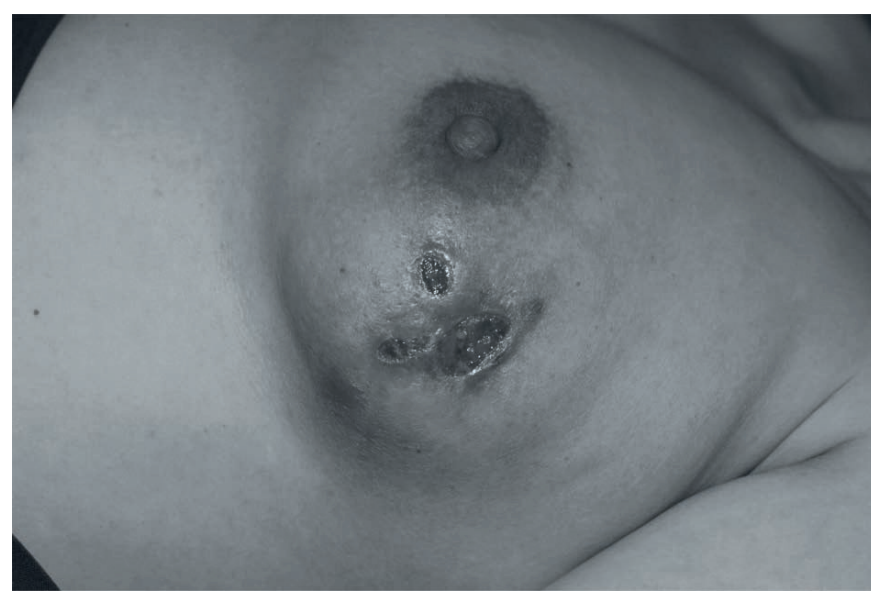

Fig. 1. View of the left breast in an IGM patient with fistula formation.

analysis carried out in 24 patients revealed benign pathology. Mastitis was described as a granulomatous inflammatory response centered on breast lobules with the absence of caseous necrosis and any specific organism.

\section{Treatment}

Cellulitis and fistula formation were seen in 19 patients at presentation. They received oral ampicillin-sulbactam therapy for 10 days preoperatively. All patients received a single dose of ampicillin-sulbactam preoperatively and another one 10 days after surgery. In the surgery-only group, wide excision was performed in all patients except 5. Pathologic examination was carried out in each patient. $64 \mathrm{mg}$ of prednisolone was given daily for 2 weeks, diminishing gradually based on the clinical and radiological findings. The minimum duration of treatment was for 8 weeks. The longest treatment period was 16 weeks and applied only to 2 patients. Regarding the surgical procedure, 8 patients underwent total excision of the mass and 66 patients were treated by wide local incision and quadrantectomy. In the total excision method, only the palpable mass itself was removed, while in the wide local excision method the mass was extracted with $1 \mathrm{~cm}$ security margin.

\section{Follow-Up}

Median follow-up was for 41 (range 3-170) months. Follow-up data were complete for $67(91.7 \%)$ of the 73 patients. Recurrence developed in 4 (7.5\%) patients in the surgeryonly group, whereas there was no recurrence in the steroidand-surgery group $(\mathrm{p}=0.19)$. In 2 patients, a mass lesion appeared in the same location of the breast 16-37 months after excision, and in the other 2 patients, abscess and fistula formation developed only 1 month after excision. The first patient with recurrence was successfully treated by reexcision, while the other patient was treated by oral steroid therapy
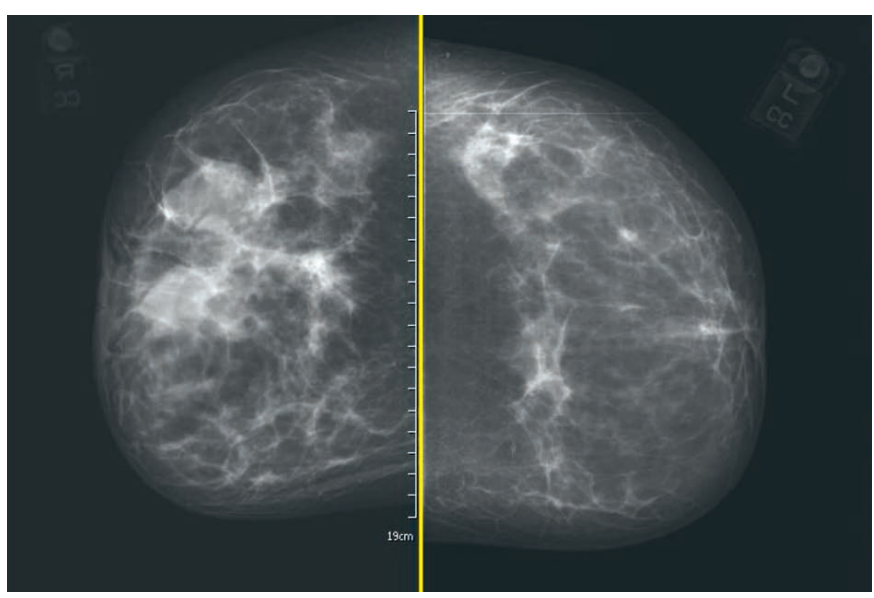

Fig. 2. MMG in a 30-year-old woman. On the craniocaudal mammogram of both breasts, a focal asymmetrical density with indistinct margins is seen in the retroareolar area of the right breast (proven to be granulomatous mastitis by histopathology).

followed by antibiotic therapy and abscess drainage because of widespread involvement. The other 2 recurrent cases were treated by combined steroid therapy and reexcision.

\section{Discussion}

IGM is a rare diagnosis with a variable clinical course and no clear etiology. It was first described as an entity by Kessler and Wolloch in 1972 [1]. Few articles exist in the literature, most of which are case reports and small series [4, 11, 12, 34]. The etiology of IGM is not clear. Many agents such as local irritants, viruses, mycotic and parasitic infections, hyperprolactinemia, diabetes mellitus, breast trauma, oral contraceptive use, and smoking have been considered, but an autoimmune reaction is favored $[1,10,13-15]$. The findings of the investigation described in this report did not clearly support any of these hypotheses. Also, the similarity between IGM and autoimmune diseases such as granulomatous thyroiditis, granulomatous prostatitis, and granulomatous orchitis and the response to steroid treatment fit in with the autoimmune hypothesis [10]. However, this hypothesis has been challenged by some authors who have found no immunologic abnormalities in such patients. There is no sound scientific evidence for any of these etiologies. Serologic and bacterial tests are usually negative [16]. Additionally, Altintoprak et al. [17] demonstrated that the role of autoimmune factors in the etiology of IGM could not be verified. No pathogenic microorganisms were detected in our series. Damage to the ductal epithelium produced by any of these etiological factors could permit luminal secretions to leak into the lobular connective tissue, thereby causing a localized immune reaction with lymphocyte and macrophage migration [13]. The diagnosis of IGM is necessary to rule out other granulomatous lesions in the breast. 


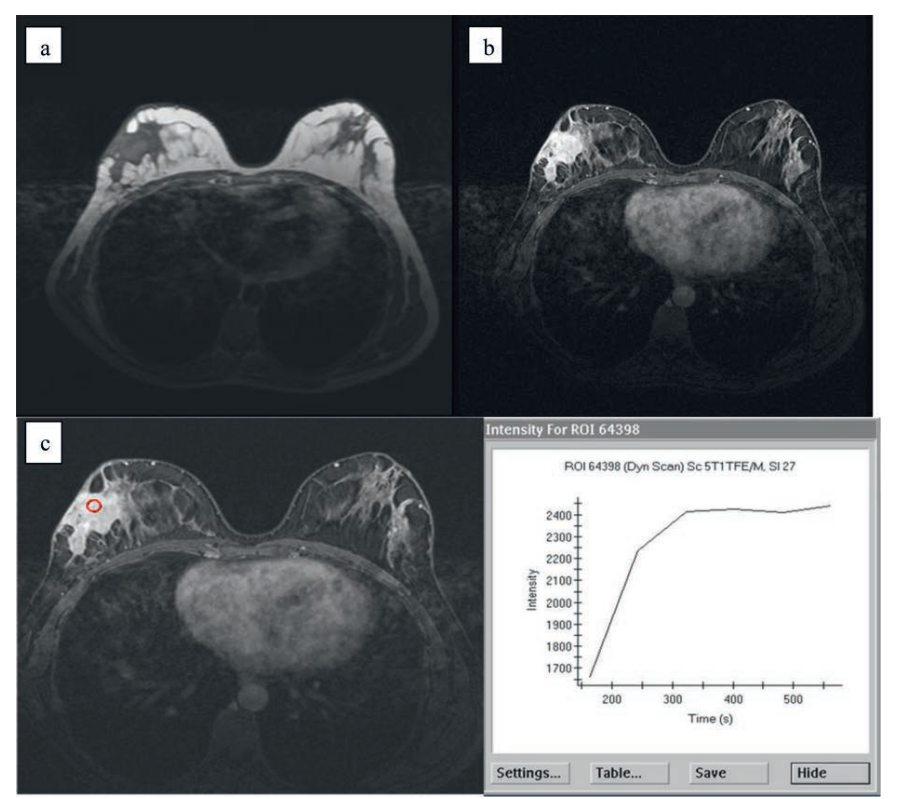

Fig. 3. MRI in a 37-year-old woman. (a) Precontrast and (b) dynamic contrast-enhanced MRI showing irregular heterogeneous enhancement in the outer quadrant of the right breast (proven to be granulomatous mastitis by histopathology), with skin involvement. (c) Type II enhancement is seen from the time-intensity curve.

Tuberculous mastitis is also an uncommon disease that is often difficult to differentiate from IGM [18]. Recently, Bani Hani et al. [14] pointed out that the largest reported series of IGM come from developing countries. Because of this, they suggested that IGM might be the reflection of underdiagnosis of tuberculosis mastitis. In these countries, tuberculosis is endemic and Bacille Calmette-Guerin (BCG) vaccination is done routinely. Positive tuberculin skin test results with no other findings of active tubercular disease probably represent past exposure to Mycobacterium species or residual reaction to BCG. The cytomorphologic pattern seen in tuberculous mastitis is indistinguishable from that seen in IGM. Since it is not always possible to detect acid-fast bacilli in histologic sections of tuberculous mastitis, accurate diagnosis can safely be made only when additional clinical data is available. Physicians must also be cautions when examining patients from high-risk populations or endemic areas, like our region. Uncommon sites and similarities with other diseases clinically and radiographically lead to diagnostic and therapeutic delays.

The optimal treatment for IGM has still not been determined because the clinical course of IGM is complex and the outcome of each treatment modality is variable [19]. Although no evidence-based therapeutic guidelines exist, attempted treatment modalities have included surgery, steroids, antibiotics, and antirheumatic agents such as methotrexate [20]. These treatment options have been described in very few articles $[9$, 21]. Antibiotics have no role in the management of true cases of IGM, but IGM is sometimes complicated by abscess forma- tion, fistulae, or chronic suppuration. Mixed aerobic and anaerobic infections may be seen and antibiotics should be used [22]. Patients with uncomplicated IGM may be observed over time without treatment [23]. Lai et al. [13] reported spontaneous complete resolution in $50 \%$ of IGM cases after a mean interval of 14.5 months. DeHertogh et al. [24] first advocated the use of corticosteroids for the treatment of IGM after the observation that a granulomatous mass disappeared within 3 weeks with administration of high-dose prednisone. Some reports also suggest that, following a diagnosis of IGM, it may be necessary to continue high doses of corticosteroids until complete resolution $[16,24]$. Satisfactory results have been reported with high doses of prednisone $(60 \mathrm{mg}$ /day for 2 weeks), but there has been reluctance due to side effects such as glucose intolerance and cushingoid features $[11,12]$. We previously showed that both treatment and diagnosis of IGM pose a considerably complex problem, suggesting steroid use only in case of recurrent and complicated cases [9]. However, after a dramatic increase in the number of patients and with some of these cases having recovered spontaneously, we changed our approach to these cases, now favoring more conservative methods. The optimal dose and methods of corticosteroid administration have not yet been established. An initial dose of $64 \mathrm{mg} /$ day of prednisolone was selected in the current series, based on the previous reports $[16,25]$. Therefore, $64 \mathrm{mg}$ of prednisolone was given daily for 2 weeks, after which the dose was slowly tapered based on the clinical and radiological findings. The minimum duration of treatment was for 8 weeks. The longest treatment period was 16 weeks and applied only to 2 patients. Sakurai et al. [26] have reported that, in 7 of 9 patients, steroid only treatment was enough without the need for surgery. However, continuation of high doses of steroid therapy for 10 months was necessary in order to completely resolve the lesions in these patients. On the other hand, in other studies, about half of the cases relapsed after discontinuation or decreasing the steroid dose $[10,27]$. Steroid treatment decreases the lesion dimensions and augments complete healing after excision [9]. It also provides significant regression of the inflammatory disease, allowing more conservative surgery. Consecutive surgical excision of the remaining lesions provides definitive treatment and reduces the risk of recurrence [28-30].

Early recognition and administration of steroid treatment might prevent repetitive, deforming breast biopsies. Erozgen et al. [31] reported a treatment dose of $16 \mathrm{mg}$ prednisolon twice a day for 2 weeks and, thereafter, the dose was slowly tapered and the therapy was stopped 2 months later. They obtained fairly satisfactory results with this dose and registered only 1 recurrence 11 months after the first therapy.

The different results obtained from the diverse studies may be explained by the notion that different factors may play a role both in the etiology and recuperation of the disease. These may be socioeconomic or ethnic factors. Future research work could provide more complete information on the 
etiology and epidemiology of IGM, including possible contributions of ethnicity and the socioeconomic status.

Despite these aggressive approaches, Lai et al. [13] suggested that expectant, conservative management with close surveillance might be the treatment modality of choice because of the self-limiting nature of IGM. Recently, Konan et al. [32] also proposed that conservative management with systemic therapy including a steroid together with azathioprine is safe and effective in the treatment of IGM. Interestingly, Al-Jarrah et al. [33] showed that IGM was successfully treated with antibiotics, except for 1 case. They also reported no recurrence in 20 cases of IGM. However, conservative management alone is a difficult decision to make because of diagnostic confusion, and may even require excision. In our opinion, systemic steroid therapy with surgical resection is the recommended first-line treatment strategy for IGM. This treatment sequence would potentially reduce surgical scarring. All of the present 21 patients who received steroid therapy achieved a cure without recurrence. We conclude that the idea to use steroid therapy only for complicated and recurrent cases should be reassessed. Increased awareness of these diseases will increase their understanding and improve their management.

\section{Conclusions}

Systemic steroid therapy with surgical resection is the recommended first-line treatment strategy for IGM. Our findings are based on a retrospective study; in the future, a randomized controlled trial should be conducted to compare surgical excision with corticosteroid therapy versus other management strategies.

\section{Disclosure Statement}

The authors declare no conflicts of interest.

\section{References}

1 Kessler E, Wolloch Y: Granulomatous mastitis: a lesion clinically simulating carcinoma: Am J Clin Pathol 1972;58:642-646.

2 Erhan Y, Veral A, Kara E, Ozdemir N, Kapkac M, Ozdedeli E, et al.: A clinicopathologic study of a rare clinical entity mimicking breast carcinoma: idiopathic granulomatous mastitis. Breast 2000;9: $52-56$

3 Asoglu O, Ozmen V, Karanlik H, Tunaci M, Cabioglu N, Igci A, et al.: Feasibility of surgical management in patients with granulomatous mastitis. Breast J 2005;11:108-114.

4 Cohen C: Granulomatous mastitis. A review of 5 cases. S Afr Med J 1977;52:14-16.

$\checkmark 5$ Tse GM, Poon CS, Ramachandram K, et al.: Granulomatous mastitis: a clinicopathological review of 26 cases. Pathology 2004:36:254-257.

6 Wilson JP, Massol N, Marshall J, Foss RM, Copeland EM, Grobmyer SR: Idiopathic granulomatous mastitis: in search of a therapeutic paradigm. Am Surg 2007;73:798-802.

7 Going JJ, Anderson TJ, Wilkinson S, Chetty U: Granulomatous lobular mastitis. J Clin Pathol 1987;40:535-540.

8 Heer R, Shrimankar J, Griffith CDM: Granulomatous mastitis can mimic breast cancer on clinical, radiological and cytological examination; a cautionary tale. Breast 2003;12:283-286.

-9 Akcan A, Akyildiz H, Deneme MA, Akgun H, Aritas Y: Granulomatous lobular mastitis: a complex diagnostic and therapeutic problem. World J Surg 2006;30:1403-1409.

10 Azlina AF, Ariza Z, Arni T, Hisham AN: Chronic granulomatous mastitis: diagnostic and therapeutic considerations. World J Surg 2003;27:515-518.

11 Ayeva-Derman M, Perrotin F, Lefrancq T, et al.: Idiopathic granulomatous mastitis: review of the literature illustrated by four cases. J Gynecol Obstet Biol Reprod 1999;28:800-807.

12 Belaabidia B, Essadki O, El Monsouri A, Squalli S: Idiopathic granulomatous mastitis; apropos of eight cases and review of the literature. Gynecol Obstet Fertil 2002;30:383-389.
13 Lai EC, Chan WC, Ma TK, Tang AP, Poon CS, Leong HT: The role of conservative tretament in idiopathic granulomatous mastitis. Breast J 2005; 11:454-456.

14 Bani Hani KE, Yaghan RJ, Matalka II, et al.: Idiopathic granulomatous mastitis: time to avoid unnecessary mastectomies. Breast J 2004;10:318322.

15 Fletcher A, Magrath IM, Riddel RH, et al.: Granulomatous mastitis: a report of seven cases. J Clin Pathol 1982;35:941-945.

16 Jorgensen MB, Nielsen DM: Diagnosis and treatment of granulomatous mastitis. Am J Med 1992; 93:97-101

17 Altintoprak F, Karakece E, Kivilcim T, Dikicier E, Cakmak G, Celebi F, et al.: Idiopathic granulomatous mastitis: an autoimmune disease? Sci World J 2013;2013:148727.

18 Seo HR, Na KY, Yim HE, Kim TH, Kang DK, Oh KK: Differential diagnosis in idiopathic granulomatous mastitis and tuberculous mastitis. J Breast Cancer 2012;15:111-118.

19 Hur SM, Cho DH, Lee SK, Choi MY, Bae SY, Koo MY: Experience of treatment of patients with granulomatous lobular mastitis. J Korean Surg Soc 2013;85:1-6.

20 Akbulut S, Yilmaz D, Bakir S: Methotrexate in the management of idiopathic granulomatous mastitis: review of 108 published cases and report of four cases. Breast J 2011;17:661-668.

21 Al-Khaffaf B, Knox F, Bundred NJ: Idiopathic granulomatous mastitis: a 25-year experince. J Am Coll Surg 2008;206:269-273.

22 Baslaim MM, Khayat HA, Al-Amoudi SA: A heterogeneous disease with variable clinical presentation. World J Surg 2007;31:1677-1681.

23 Schelfout K, Tjalma WA, Cooremans ID, Coeman DC, Colpaert CG, Buytaert PM: Observations of an idiopathic granulomatous mastitis. Eur J Obstet Gynecol Reprod Biol 2001;97:260-262.

24 DeHertogh D, Rossof A, Harris AA, Economou SG: Prednisone management of granulomatous mastitis. N Eng J Med 1980;303:799-800.
25 Sato N, Yamashita H, Kozaki N, Watanabe Y, Ohtsuka Y, Kuroki S, et al.: Granulomatous mastitis diagnosed and followed up by fine-needle aspiration cytology, and successfully treated by corticosteroid therapy: report of case. Surg Today 1996; 26:730-733

26 Sakurai T, Oura S, Tanino H, Yoshimasu T, Kokawa Y, Kinoshita T, Okamura Y: A case of granulomatous mastitis mimicking breast carcinoma. Breast Cancer 2002;9:365-268.

27 Kim J, Tymms KE, Buckingham JM: Methotrexate in the management of granulomatous mastitis. ANZ J Surg 2003;73:247-249.

28 Gurleyik G, Aktekin A, Aker F, Karagulle H, Saglamc A: Medical and surgical treatment of idiopathic granulomatous lobular mastitis: a benign inflammatory disease mimicking invasive carcinoma. J Breast Cancer 2012;15:119-123.

29 Mohammed S, Statz A, Lacross JS, Lassinger BK, Contreras A, Gutierrez C, et al.: Granulomatous mastitis: a 10 year experience from a large inner city county hospital. J Surg Res 2013;184:299-303.

-30 Kayahan M, Kadioglu H, Muslumanoglu M: Management of patients with granulomatous mastitis: analysis of 31 cases. Breast Care (Basel) 2012;7:226-230.

31 Erozgen F, Ersoy YE, Akaydin M, Memmi N Celik AS, Celebi F, et al.: Corticosteroid treatment and timing of surgery in idiopathic granulomatous mastitis confusing with breast carcinoma. Breast Cancer Res Treat 2010;123:447-452.

32 Konan A, Kalyoncu U, Dogan I, Kiliç YA, Karakoç D, Akdogan A, et al.: Combined longterm steroid and immunosuppressive treatment regimen in granulomatous mastitis. Breast Care (Basel) 2012;7:297-301.

33 Al-Jarrah A, Taranikanti V, Lakhtakia R, Al-Jabri A, Sawhney S: Idiopathic granulomatous mastitis: diagnostic strategy and therapeutic implications in Omani patients. Sultan Qaboos Univ Med J 2013; 13:241-247.

34 Kayahan M, Kadioglu H, Muslumanoglu M: Management of patients with granulomatous mastitis: analysis of 31 cases. Breast Care 2012;7:226-230. 